\title{
Surgery and Global Health: A View from Beyond the OR
}

\author{
Paul E. Farmer · Jim Y. Kim
}

Published online: 3 March 2008

(C) The Author(s) 2008

\section{The neglected stepchild of global health}

In Africa, surgery may be thought of as the neglected stepchild of global public health. There are fewer physicians per population on this continent than on any other; surgeons are rarer still, and almost all of them work in the urban enclaves of what remains a rural region. The story is the same in the poorer parts of Asia and Latin America (with a few exceptions, such as Cuba). Although disease treatable by surgery remains a ranking killer of the world's poor, major financers of public health have shown that they do not regard surgical disease as a priority even though, for example, more than 500,000 women die each year in childbirth; these deaths are largely attributable to an

\section{P. E. Farmer $(\square)$}

Program in Infectious Disease and Social Change, Department of Social Medicine, Harvard Medical School, 641 Huntington

Avenue, Boston, Massachusetts 02115, USA

e-mail: paul_farmer@hms.harvard.edu

\section{P. E. Farmer · J. Y. Kim}

Division of Social Medicine and Health Inequalities, Department of Medicine, Brigham and Women's Hospital, 651 Huntington Avenue, Boston, Massachusetts 02115, USA

\section{P. E. Farmer}

Partners In Health, 641 Huntington Avenue, Boston,

Massachusetts 02115, USA

\section{J. Y. Kim}

Department of Social Medicine, Harvard Medical School, 641

Huntington Avenue, Boston, Massachusetts 02115, USA

\section{J. Y. Kim}

François-Xavier Bagnoud Center for Health and Human Rights, Harvard School of Public Health, 677 Huntington Avenue, Boston, Massachusetts 02115, USA absence of surgical services and other means of stopping post-partum hemorrhage [1]. Equally unattended, among the very poor, are motor-vehicle and farm accidents, peritonitis, long-bone fractures, and even blindness [2-4]. Cardiac disease, congenital or the sequela of infection, is a death sentence for most people-many of them childrenso afflicted in the poorest parts of the world [5, 6]. In some settings, surveys reveal that surgical disease is among the top 15 causes of disability [7], and surgical conditions account for up to $15 \%$ of total disability adjusted life years (DALYs) lost worldwide [8].

If it is true that surgery is the neglected stepchild of global health, does it follow that there are no surgical services available in the poor world? The truth is even more unpleasant: within poor countries, surgical services are concentrated almost wholly in cities and reserved largely for those who can pay for them. In Haiti, for example, a community-based survey conducted in the 1980s suggested that rates of caesarian section in a large area of southern Haiti were close to zero; maternal mortality was pegged at 1,400 per 100,000 live births [9]. Yet among the affluent of that same country, rates of caesarian section do not vary much from those registered in the United States. Careful scrutiny of local inequalities of risk and access to care reveals that in poor countries, even minor surgical pathologies are often transformed through time and inattention into lethal conditions. Congenital abnormalities such as cleft palate remain life-long afflictions rather than pediatric surgical disease. In addition to surgical abdomens, severe trauma (from road accidents more often than from intentional violence) and other potentially fatal pathologies remain a massive burden of untreated disease that weighs on the lives, and productivity, of the world's bottom billion. 
When we at the non-governmental organization Partners In Health (PIH) asked ourselves, in rural central Haiti, whether or not we would let ability to pay even the smallest fee determine who would have access to surgical care, we decided to approach surgical disease as we did AIDS or tuberculosis. Unless we waived fees, we would most certainly exclude some of the very people we had come to serve in the first place. We were not surprised when we became the region's, then the country's, de facto provider of last resort. The only way to decrease the caseload in our hospital would be to strengthen the area's public hospitals and permit them to offer equivalent services, also as a public good for public health [10]. It is noteworthy that the only significant advance in the effort to make surgical care something other than a commodity has been with respect to caesarian sections. In August 2007, the district health commissioner for central Haiti, faced with staggering local inequalities in maternal mortality, announced that all prenatal care and emergency obstetrical services would from then on be available free of charge to the patient.

\section{Accounting for inattention}

Why has surgical disease been so neglected in global health? For one thing, international health has been dominated for decades by those concerned with communicable disease, from smallpox to AIDS [11]. This was welcome, even though the majority of premature deaths are not attributable to infections and the distinction between communicable and noncommunicable diseases is not always important: some surgical disease may be classed as communicable, while many infectious diseases are not readily communicable. That said, most pathologies requiring surgical interventions are not transmissible from one person to another and thus do not rank as a public problem necessitating public support. In the absence of public funding or widespread health insurance, the treatment of surgical disease hinges on a means test: can the patient and family pay for the services? As we have learned in Haiti and beyond, fee-for-service surgical care simply removes the poorest sector of the population from the equation, unless the calculus of interest accounts for mortality.

Another reason for the relative inattention to surgery in global health is that only now are significant numbers of surgeons involving themselves in such matters. We need our surgical colleagues to speak fluently about rebuilding infrastructure, training personnel, and delivering highquality care to the very poorest. It took decades of advocacy to develop funding mechanisms for AIDS prevention and care. Tuberculosis, neglected for decades, was declared a priority by the World Bank only after efforts were made to show that it was in fact a leading killer of young adults worldwide and far from being eradicated. The World Health Organization and the Gates Foundation have announced plans to address malaria and other neglected diseases of poverty. But there is no Global Fund for Surgery, and rare indeed are the foundations willing to support surgery as an important part of global public health. Even efforts to address maternal mortality are too timid if they suggest that anything less than the full panoply of modern obstetrics-including surgery, antihemorrhagics, and blood banking_will reduce deaths during childbirth.

Another reason for reluctance is the simple truth that surgery is most often a highly complex intervention. There are exceptions-innovation in cataract removal is often cited-but surgery usually requires not only a surgeon but anesthesia, an operating room, autoclaves, sutures, drapes, and other supplies, not to mention postoperative care and blood banking. There is no surgical equivalent to a vaccination campaign or a mosquito net. To do surgery properly requires a significant investment in infrastructure and training as well as a steady supply of consumables.

\section{What is to be done?}

We have hinted at a long-term vision of the role of surgery in global public health. This vision is ambitious: key surgical services must always be available within the public sector, and free of charge at the point of care if charges can be shown to serve as barriers for the poor. None of this will be accomplished unless we take a series of steps right away. In an article in this issue of the World Journal of Surgery, we present our own experience in rural Haiti once user fees for surgery were abolished. This often-painful experience has led us to hold strong views on the role of surgery in global health.

Allow us to offer other suggestions from beyond the OR. Some of these will sound like stop-gap measures, and they are. Many are already underway but need to be improved dramatically. For example, "twinning programs" already link first-world hospitals to those based in poor countries. The problem is that many of the latter do not provide surgical services to the poorest, as anyone can discover merely by examining the hospitals' fee structures and assessing the ability of the region's poorest people to pay. Twinning programs should not be abandoned, since that would further slow the movement of resources down the steep slope of inequality toward those who need such care most. However, donor hospitals, surgeons, and all those involved in efforts to redistribute surgical supplies need to do due diligence and rate their partner institutions in new ways. Do not merely ask about the size and quality of the operating rooms. Ask about your partners' commitment to reaching the poorest. 
The growing proximity of rich world and poor has also led to a proliferation of short-term medical missions to address the health problems of those living in extreme poverty. Although we and many others have argued that primary health care, requiring sustained investment of time and resources, cannot be delivered effectively through such missions, this critique does not always hold true for certain surgical subspecialties [12]. Witness the success of what might be termed "vertical" surgical missions focusing on a single pathology, such as cleft palate or cataracts.

Again, we would not suggest abandoning short-term medical missions. Rather, how can we do them better? It is important to integrate vertical surgical programs into broader efforts to improve public health in general. This means, again, doing due diligence. After asking how well partner institutions (hospitals, clinics, medical schools) do in providing, for example, cataract care to the poorest, a second tier of questions follows: How well are partner institutions serving the broader goals of public health? Of the primary health care movement? Of global health equity? [13, 14]. These questions remind us that global health need not be a competitive race for scarce resources. If we join forces with international health experts, with activists, and with those setting health policies, we can build a coherent movement that comes to include surgery. Many issues can unite us; addressing maternal mortality should be a priority that drives forward the broader surgical and public health agendas.

We must also contribute to building or rebuilding infrastructure in the public sector, since a strong public sector is the only guarantor of access to health care as a right. In Latin America and in Africa, we have focused our efforts within the public sector, usually starting at the level of the district (a unit typically containing hundreds of thousands of people). Having an operating room is only the first of several steps; all hospitals with surgical programs need postoperative care and blood-banking. In fact, even a small district hospital needs at least two operating theaters (one for emergencies, usually obstetric, and another for elective cases), a blood bank on site, a laboratory, anesthesia machines and staff who know how to use and repair them, and an uninterrupted source of electricity.

Surgeons who wish to donate their time to the needy in resource-poor settings learn immediately about the need for bricks and mortar, generators, autoclaves, and staff. First-world surgeons are unaccustomed to having to recruit and manage barely literate but well-meaning helpers, much less to build and stock their own operating rooms. Clearly, we do not want surgeons to be dragged out of the operating room to manage logistics, supply chains, the training of paraprofessionals, and financing. But we do need the support and attention of surgeons if progress is to be made.
Global health currently attracts unprecedented interest among surgeons, especially those in training, for whom residency programs and fellowships should be further developed, as is now occurring in medicine [15]. Field experience remains an important teacher. Providing even the most basic surgical services to those previously unserved requires infrastructure, training, supplies, and experienced personnel. The one thing not required is surgical disease, which exists abundantly among the world's poorest. To bring a greater number of surgeons into the campaign for public health unrestricted by ability to pay will involve enlarging the horizons of both the surgical and public-health professions.

Acknowledgment This work was in part supported by National Institute of Allergy and Infectious Disease (K23 AI063998 to LCI).

Open Access This article is distributed under the terms of the Creative Commons Attribution Noncommercial License which permits any noncommercial use, distribution, and reproduction in any medium, provided the original author(s) and source are credited.

\section{References}

1. World Health Organization (2005) World health report 2005: making every mother and child count. Available at http://www.who.int/whr/2005/whr2005_en.pdf (accessed 4 January 2008)

2. Beveridge M, Howard A (2004) The burden of orthopaedic disease in developing countries. J Bone Joint Surg Am 86:18191822

3. World Health Organization (2004) World report on road traffic injury prevention. Available at http://www.who.int/violence injury_prevention/publications/road_traffic/world_report/ summary_en_rev.pdf (accessed 4 January 2008)

4. Yorston D (2005) High-volume surgery in developing countries. Eye 19:1083-1089

5. Cox JL (2001) Presidential address: changing boundaries. J Thorac Cardiovasc Surg 122:413-418

6. Rao SG (2007) Pediatric cardiac surgery in developing countries. Pediatr Cardiol 28:144-148

7. Mathers CD, Loncar D (2006) Projections of global mortality and burden of disease from 2002 to 2030. PLoS Med 3(11):20112030

8. Debas HT, Gosselin R, McCord C et al (2006) Surgery. In: Disease control priorities in developing countries, 2nd ed. Oxford University Press, New York, pp 1245-1260

9. Jean-Louis R (1989) Diagnostic de l'état de santé en Haïti. Forum Libre I (Médecine, Santé et Démocratie en Haïti) 11-20

10. Kim JY, Shakow A, Castro A et al (2003) Tuberculosis control. In: Smith R, Beaglehole R, Woodward D et al (eds), Global public goods for health: health economic and public health perspectives. Oxford University Press for the World Health Organization, New York, pp 54-72

11. Kim JY, Farmer P (2008) Global issues in medicine. In: Fauci AS, Kasper DL, Braunwald E et al (eds), Harrison's principles of internal medicine, 17th ed. McGraw-Hill, New York

12. Wright IG, Walker IA, Yacoub MH (2007) Specialist surgery in the developing world: luxury or necessity? Anaesthesia 62(Suppl 1):84-89 
13. Walton DA, Farmer PE, Lambert W et al (2004) Integrated HIV prevention and care strengthens primary health care: lessons from rural Haiti. J Public Health Policy 25(2):137-158

14. Farmer P (2007) From "marvelous momentum" to healthcare for all. Response to Garrett L: The challenge of global health. Special feature on "How to promote global health." Foreign Affairs,
January 23, 2007. Available at http://www.foreignaffairs.org/ special/global_health/ [In print, Foreign Affairs 2007 MarchApril, pp 155-159]

15. Furin J, Farmer P, Wolf M et al (2006) A novel training model to address health problems in poor and underserved populations. J Health Care Poor Underserved 17(1):17-24 